\title{
Identification of a potent adipocyte-specific enhancer: involvement of an NF-1-like factor
}

\author{
Reed A. Graves, Peter Tontonoz, Susan R. Ross, ${ }^{1}$ and Bruce M. Spiegelman ${ }^{2}$ \\ Dana-Farber Cancer Institute and the Department of Biological Chemistry and Molecular Pharmacology, Harvard Medical \\ School, Boston, Massachusetts 02115 USA; 'Department of Biochemistry, University of Illinois Medical School, Chicago, \\ Illinois 60612
}

The molecular basis for adipocyte-specific gene expression is not known. We have demonstrated that while short $(-168)$ segments of the 5 '-flanking sequence of the adipocyte P2 gene containing AP-1- and C/EBP-binding sites can direct expression of a heterologous gene in cultured adipocytes, they cannot support tissue-specific expression in a transgenic mouse. We have therefore analyzed larger segments of the aP2 5 '-flanking region by transfection into adipocytes and have found an enhancer at $-5.4 \mathrm{~kb}$. This $500-\mathrm{bp}$ enhancer directs expression of the bacterial chloramphenicol acetyltransferase (CAT) gene in a differentiation-dependent fashion when linked to its own minimal promoter or to an enhancerless SV40 promoter. Moreover, this enhancer stimulates very strong and highly specific expression from the CAT gene in the adipose tissues of transgenic mice. A smaller fragment (190 bp) having enhancer activity in adipocytes was defined and demonstrated to contain a binding site for an abundant nuclear protein. This factor has the binding specificity and several other properties characteristic of the nuclear factor 1 (NF-1) transcription/replication factor family, and mutation of this NF-1-binding site greatly reduces the function of the 500-bp enhancer. These results identify and characterize the first functional enhancer with specificity for adipose cells and also demonstrate that a member(s) of the NF-1 family is involved in adipocyte-specific gene expression.

[Key Words: Adipocyte P2 gene; adipocyte transcription factor; differentiation-dependent enhancer; nuclear factor 1; tissue-specific enhancer]

Received October 31, 1990; revised version accepted December 27, 1990.

Adipocytes play a central role in maintaining the energy balance of vertebrate animals. These cells store energy in the form of triglycerides during periods of nutritional abundance and release it in a biochemically useful form at times of nutritional deprivation. This switch between lipogenic and lipolytic states is under the tight control of a number of hormones, most notably insulin and catecholamines. Pathological conditions associated with altered adipose cell number and/or function include obesity and several lipodystrophy syndromes.

Preadipocytes are fibroblast-like cells that differentiate into adipocytes. Many established preadipocyte cell lines are now available that differentiate at high frequency into adipocytes under appropriate culture conditions (Green and Kehinde 1974; Green and Kehinde 1976; Negrel et al. 1978; Chapman et al. 1984). The resulting cultured adipocytes have most, but not all, of the properties of adipose cells in vivo (Green and Kehinde 1976; Green 1979).

Adipocyte differentiation is accompanied by the tran-

${ }^{2}$ Corresponding author. scriptional activation of many genes, some of which have been cloned at the cDNA level (Spiegelman et al. 1983; Bernlohr et al. 1984, 1985; Chapman et al. 1984; Cook et al. 1985; Diian et al. 1985; Doglio et al. 1986). As expected, many of these encode gene products involved in lipid metabolism, while some encode previously undescribed proteins. One novel gene product is adipocyte P2 (aP2), a very abundant adipocyte-specific member of the large family of intracellular lipid carrier proteins that includes the liver, heart, and intestinal fatty acid-binding proteins (Bernlohr et al. 1984; Cook et al. 1985). aP2 has been demonstrated to bind several fatty acids including retinoic acid (Matarese and Bernlohr 1988), though its precise physiological role is not known.

The promoter of the aP2 gene has been isolated and used as a model for the study of differentiation-linked and hormonally linked gene regulation (Hunt et al. 1986; Phillips et al. 1986; Cook et al. 1988). Sequences from the aP2 proximal promoter $(-247$ or -168 to +21$)$ have been shown to direct differentiation-dependent expression of bacterial chloramphenicol acetyltransferase (CAT) upon transient transfection into preadipocytes 
and adipocytes (Distel et al. 1987; Cook et al. 1988; Christy et al. 1989; Yang et al. 1989). Several regulatory elements that strongly influence this expression have been identified. These include an AP-1 site at -120 , where a sequence-specific interaction between Fos-containing protein complexes and DNA was first demonstrated (Distel et al. 1987; Rauscher et al. 1988). An additional positive-acting element at position -140 was shown to bind the transcription factor C/EBP in extracts from adipose cells, and a distinct protein from preadipocyte extracts (Christy et al. 1989; Herrera et al. 1989). Both the AP-1- and C/EBP-binding sites have been shown to function positively in adipose cells, and the AP-1 site is required for response of this promoter to cyclic AMP analogs (Christy et al. 1989; Herrera et al. 1989).

At present, the cis-acting sequences that regulate the differentiation-dependent and tissue-specific expression of the aP2 gene have not been precisely defined. Indeed, no functional enhancer from any gene with a specificity for adipose cells has been reported. In this study we have investigated a large region of the aP2 gene $5^{\prime}$-flanking sequence and have found a cis-acting element capable of directing high-level gene expression in cultured adipocytes, as well as the adipose tissue of transgenic mice. Further dissection and analysis of this fat-specific enhancer has identified a key trans-acting factor as a member of the nuclear factor 1 (NF-1) family of regulatory proteins.

\section{Results \\ Identification of an adipose cell enhancer}

Previous work has demonstrated that CAT constructs containing short DNA segments from the 5 '-flanking region of the aP2 gene $(-247$ or -168 to +21$)$ are expressed preferentially in cultured adipocytes (Distel et al. 1987; Cook et al. 1988; Christy et al. 1989; Herrera et al. 1989). However, these constructs were not able to direct expression specifically to the adipose tissue of transgenic mice (Ross et al. 1990), suggesting that additional cisacting sequences are required for appropriate tissue-specific expression. With the goal of identifying these sequences, we transfected a number of constructs containing the bacterial CAT gene linked to larger regions of the aP2 promoter into 3T3-F442A adipocytes (Fig. 1). A map of the aP2 promoter is shown in Figure $2 \mathrm{~A}$, and the known transcription factor-binding sites are indicated (Distel et al. 1987; Christy et al. 1989; Herrera et al. 1989). Note that position +21 represents the $3^{\prime}$ end of all aP2CAT constructs and provides the cap site as well as a 21-nucleotide leader sequence for CAT mRNA.

Figure 1 shows the level of CAT activity obtained with constructs containing aP2 promoter fragments extending from -63 to $+21(-63 \mathrm{aP} 2 \mathrm{CAT}$; previously $-64 \mathrm{aP2}$ CAT in Distel et al. 1987), -168 to $+21(-168 \mathrm{aP2}$ $\mathrm{CAT})$, or $-5.4 \mathrm{~kb}$ to $+21(-5.4 \mathrm{aP} 2 \mathrm{CAT})$. As described in previous work, minimal CAT activity was observed with the $-63 \mathrm{aP2CAT}$ construct, which lacks the CAAT

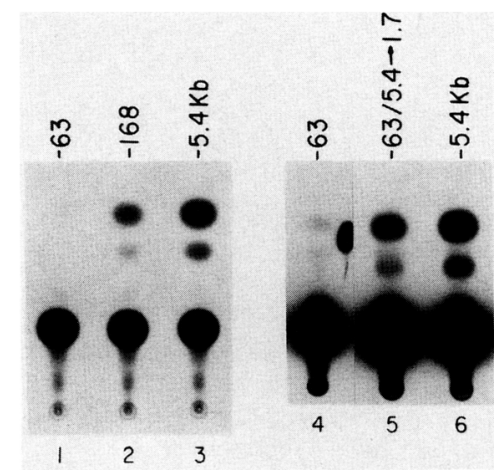

Figure 1. Identification of an upstream activator in the aP2 promoter. Adipocytes $(100-\mathrm{mm}$ dish) were transfected by calcium phosphate coprecipitation with $10 \mu \mathrm{g}$ of DNA (lanes 1-3) or DEAE-dextran adsorption with $20 \mu \mathrm{g}$ of DNA (lanes 4-6). The cells were collected $48 \mathrm{hr}$ later, and extracts were prepared by four freeze-thaw cycles. Half of the extract $(\sim 100 \mu \mathrm{g}$ of protein) was assayed for $1 \mathrm{hr}$ (lanes $1-3$ ) or $3 \mathrm{hr}$ (lanes 4-6) at $37^{\circ} \mathrm{C}$. The plasmids used contain segments from the aP2 gene linked to the promoterless pUC-CAT vector (Distel et al. 1987). (Lanes 1 and 4$)-63$ to +21 ; (lane 2) -168 to +21 ; (lanes 3 and 6$)-5.4$ $\mathrm{kb}$ to +21 ; (lane 5) $3.7-\mathrm{kb}$ fragment extending from -5.4 to $-1.7 \mathrm{~kb}$ was joined to the -63 to +21 promoter. The -63 to +21 aP2 promoter joined to pUC-CAT is referred to as -63aP2CAT here; this same construct is referred to as -64aP2CAT in Distel et al. (1987).

box, AP-1, and C/EBP-binding sites (Fig. 2A), while significant CAT activity was observed with the - 168aP2CAT construct (Distel et al. 1987). A construct that includes sequence from $-1.7 \mathrm{~kb}$ to +21 (EcoRI to +21 ; Fig. 2A) showed no enhancement of CAT activity relative to $-168 \mathrm{aP2CAT}$ (not shown), but a construct including $5.4 \mathrm{~kb}$ of the aP2 promoter (EcoRI site; Fig. 2A) showed significantly higher activity than - 168aP2CAT (Fig. 1, lane 3). These results strongly suggested that an additional positive-acting regulatory element was located between -5.4 and $-1.7 \mathrm{~kb}$. This DNA fragment was therefore isolated and ligated upstream of -63aP2CAT, which contains only a TATA box and a single FSE1 element (Fig. 2A; Hunt et al. 1986). In this context, the -5.4 - to $-1.7-\mathrm{kb}$ fragment stimulates a significant increase in CAT activity (Fig. 1, lane 5), indicating that this region contains one or more elements that can enhance heterologous gene expression in cultured adipocytes.

This 3.7-kb EcoRI-EcoRI fragment was dissected using a variety of restriction enzymes, and selected fragments were ligated to the $-63 \mathrm{aP2CAT}$ plasmid (Fig. 2B). Upon transfection into adipocytes, a greatly increased level of CAT activity was observed when the plasmids contained either the -5.4- to $-3.0-\mathrm{kb}$ (EcoRI-BamHI), -5.4- to -3.7-kb (EcoRI-PvuII), or -5.4- to $-4.9-\mathrm{kb}$ (EcoRI$\mathrm{XbaI} ;-63 / 5.4 \rightarrow 4.9 \mathrm{aP2CAT}$ ) fragments (Fig. 2A,B). Quantitatively, there was little, if any, loss of activity as progressively smaller fragments were used (data not shown). Five additional fragments spanning the region 
Figure 2. Schematic map and enhancer activity analysis of the aP2 gene. $(A)$ The $-5.4-\mathrm{kb}$ to +21 segment of the aP2 gene that was analyzed is shown. Previously identified binding sites for the transcription factors AP1 and C/EBP, as well as the CCAAT and TATA box homologies, are indicated as boxes. Note that the inverted CCAAT box is partially deleted in the -63aP2CAT construct. A detailed restriction map of the $3.7-\mathrm{kb}$ EcoRI fragment $(-5.4$ to $-1.7 \mathrm{~kb})$ that has a tissue-specific activation function is shown in the lower portion of $A$. The sites indicated were used to isolate the various restriction fragments indicated in $B .(B)$ Various restriction fragments (indicated as boxes) were ligated to the $-63 \mathrm{aP2CAT}$ vector, and the resulting constructs were then transfected into adipocytes as described in Fig. 1 . The enhancing activity of the fragment is indicated by dark shading of the boxes as well as a $+/-$ at right. (Bottom) A restriction map of the 500-bp fragment that possessed the tissuespecific enhancing activity is shown.
A

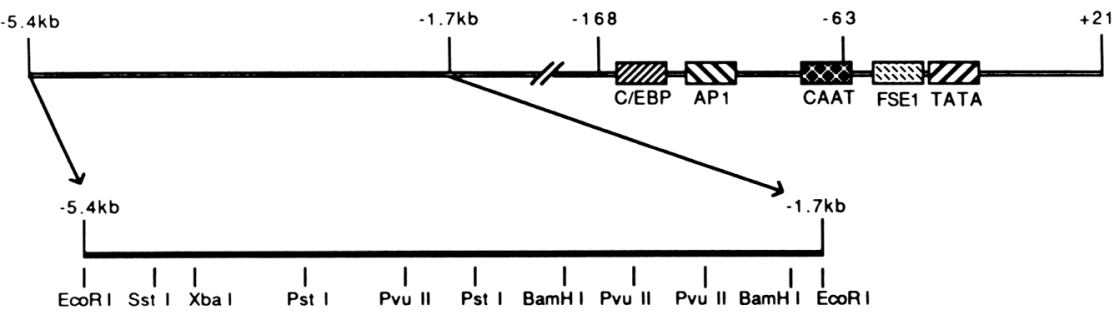

B

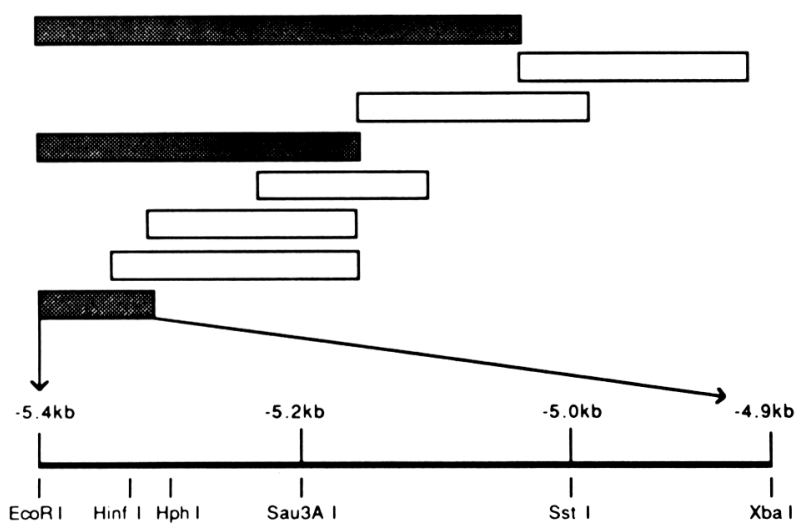

Relative Enhancing Activity of Fragment

$+$

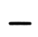

$-$

$+$

$-$

$-$ from -1.7 to $-4.9 \mathrm{~kb}$ had no effect on CAT expression (Fig. 2B). Together, these data are consistent with the presence of one or more positive-acting element(s) in the 500 -bp fragment between -5.4 and $-4.9 \mathrm{~kb}$.

\section{Differentiation dependence of the enhancer}

The differentiation-dependent and tissue-specific expression stimulated by this 500 -bp fragment was analyzed in both cultured cells and transgenic animals. In transiently transfected preadipocytes, the -5.4 - to $-4.9-\mathrm{kb}$ fragment was not able to stimulate expression from the $-63 \mathrm{aP2}$ promoter (Fig. 3, lanes 1 and 2). In contrast, when the identical constructs were transfected into fully differentiated adipocytes, a large stimulation by the -5.4- to -4.9 -kb fragment was observed (Fig. 3, lanes 5 and 6). To control for possible differences in transfection and translational efficiency of preadipocytes and adipocytes, two CAT expression vectors driven by viral promoters (the RSV and AKV long terminal repeats) were transfected and assayed in parallel (Fig. 3, lanes 3, 4, 7, and 8 ).

To compare more directly the activity of the 500-bp enhancer in preadipocytes and adipocytes, the $-63 / 5.4 \rightarrow 4.9 \mathrm{aP2CAT}$ construct was cotransfected with a neomycin-resistance-inducing plasmid into 3T3F442A preadipocytes, and a pool of 36 stable transfectants was isolated. This pool was then assayed for CAT activity both before and after differentiation. As shown in Figure 3, lanes 9 and 10, CAT expression in the
$-63 / 5.4 \rightarrow 4.9 \mathrm{aP2CAT}$ stable transfectants is stimulated at least 15 -fold per unit of protein extract upon cell differentiation. These results demonstrate clearly that the enhancer is activated upon differentiation of the cells into adipocytes.

We have also asked whether the function of the upstream 500-bp fragment depends on the aP2 proximal promoter sequences or whether it can function in conjunction with a heterologous promoter. Table 1 illustrates that the -5.4 - to $-4.9-\mathrm{kb}$ fragment also stimulates CAT expression from an enhancerless SV40 promoter (pSVIB) in an adipocyte-specific manner. Hence, the upstream enhancer appears to stimulate differentiation-dependent expression in the context of a non-tissuespecific viral promoter. The adipocyte enhancer stimulates tissue-specific
expression in transgenic mice

We then examined whether the differentiation dependence of expression derived from this aP2 gene fragment in cultured cells reflected a tissue specificity that could be observed in vivo in a transgenic mouse model system. The relevant portion of the $-63 / 5.4 \rightarrow 4.9 \mathrm{aP2CAT}$ construct was excised from the vector backbone and injected into the pronucleus of zygotes from Swiss Webster mice. Several independent founder mice were obtained, bred, and $G_{1}$ generation progeny were examined for the tissue specificity of CAT enzyme activity. Figure 4 illustrates that CAT activity was extremely high in adipose tissues, 


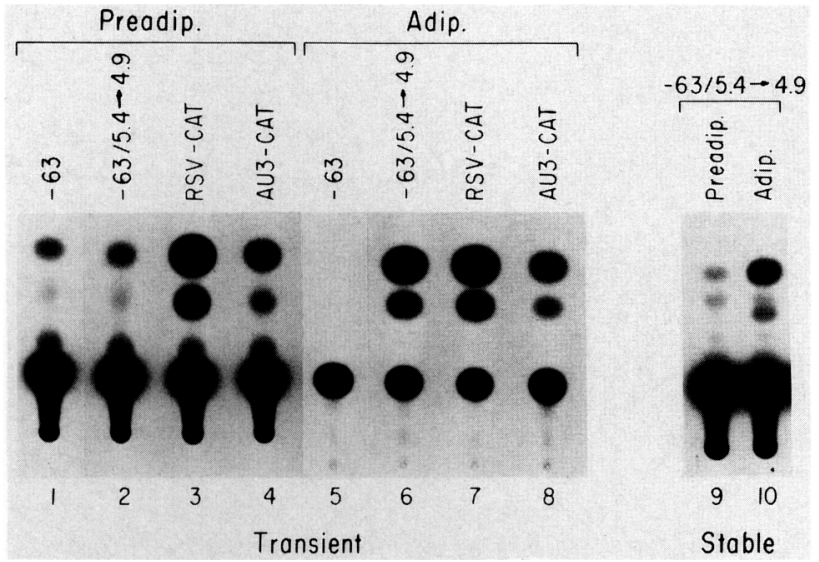

Figure 3. Differentiation-dependent activation by the -5.4 - to $-4.9-\mathrm{kb}$ fragment. The 500-bp fragment (EcoRI-XbaI; Fig. 2B) was inserted into the $-63 \mathrm{aP} 2 \mathrm{CAT}$ vector in an inverted orientation, i.e., the $E c o$ RI site $(-5.4 \mathrm{~kb})$ is joined to the -63 site and the $X b a I$ site $(-4.9 \mathrm{~kb})$ is at the $5^{\prime}$ end of the construct. This construct is designated $-63 / 5.4 \rightarrow 4.9$. Preadipocytes (lanes 1 4) or adipocytes (lanes 5-8) were transiently transfected by calcium phosphate coprecipitation with $10 \mu \mathrm{g}$ of $-63 \mathrm{aP2CAT}$ (lanes 1 and 5 ); $10 \mu \mathrm{g}$ of $-63 / 5.4 \rightarrow 4.9 \mathrm{aP2CAT}$ (lanes 2 and 6 ); $5 \mu \mathrm{g}$ of RSVCAT (lanes 3 and 7 ); $1 \mu \mathrm{g}$ of AU3CAT (lanes 4 and 8). CAT assays were performed as described in Materials and methods. This experiment was repeated seven times with five different DNA preparations and similar results were obtained. The $-63 / 5.4 \rightarrow 4.9 \mathrm{aP2CAT}$ construct was stably transfected into preadipocytes with a neomycin-resistance plasmid, and a pool of 36 colonies was expanded. Extracts from preadipocyte and adipocyte cultures were prepared, and $70 \mu \mathrm{g}$ of extract protein from each cell type was assayed for CAT activity under identical conditions (lanes 9 and 10 ).

both white (F) and brown (BF). Expression from most other tissues, including brain (BR), muscle (SM), liver (LI), and salivary gland (SG), was very low or undetectable. Quantitatively, the white adipose tissue had at least a 30-fold higher level of expression of CAT activity

Table 1. Action of the adipocyte enhancer activates the SV40 early promoter

\begin{tabular}{lcc}
\hline & \multicolumn{2}{c}{ CAT conversion $(\%)$} \\
\cline { 2 - 3 } Vector & preadipocyte & adipocyte \\
\hline pSVIB & 0.5 & 0.7 \\
pSVIB $/ 5.4 \rightarrow 4.9$ & 0.4 & 5.4 \\
\hline
\end{tabular}

The 500-bp EcoRI-XbaI fragment enhancer was ligated to the $B g$ III site of the enhancerless vector pSVIB (Celander and Haseltine 1984). Duplicate plates $(100 \mathrm{~mm}$ ) of preadipocytes or adipocytes were transfected by calcium phosphate coprecipitation with $10 \mu \mathrm{g}$ of plasmid DNA, and CAT activity was assayed as described in Materials and methods. Quantitation was done by phosphorimaging (Molecular Dynamics) of the thin-layer plates, and results showed $<20 \%$ variation between duplicates. The experiment was repeated six times, and similar results were obtained.

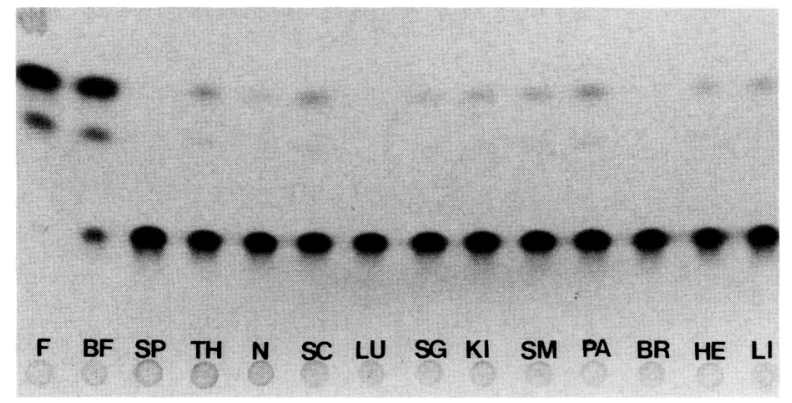

Figure 4. Tissue-specific activity of the enhancer in transgenic mice. Transgenic mice containing the $-63 / 5.4 \rightarrow 4.9$ construct were made as described in Materials and methods. CAT activity from several tissues of a $G_{1}$ generation transgenic mouse containing the $-63 / 5.4 \rightarrow 4.9 \mathrm{aP} 2 \mathrm{CAT}$ transgene is shown. Extracts from all tissues were assayed with $20 \mu \mathrm{g}$ of protein for $1 \mathrm{hr}$. This transgenic animal had $\sim 10$ copies of the transgene as determined by quantitative dot blot analysis. (F) White fat; (BF) brown fat; (SP) spleen; (TH) thymus; (N) sciatic nerve; (SC) spinal cord; (LU) lung; (SG) salivary gland; (KI) kidney; (SM) smooth muscle; (PA) pancreas; (BR) brain; (HE) heart; (LI) liver.

than any of the nonadipose tissues. Adipose tissue specificity of CAT expression was also observed in two other independently derived strains of mice. To ensure that the CAT activity observed here reflected correctly initiated mRNA transcription, RNase protection assays were performed utilizing a probe that spanned the junction between the CAT and aP2 gene. The results demonstrated that CAT mRNA was expressed specifically in adipose tissue and was initiated at the expected site $1+1$ of the aP2 gene; data not shown). It is important to note that the enhancing activity of this fragment is extremely strong as well as specific. The CAT assay shown reflects a reaction time of $1 \mathrm{hr}$ with $20 \mu \mathrm{g}$ of protein extract. The absolute activity is one of the highest levels that we have observed in transgenic mice, exceeding the levels obtained with viral promoters/enhancers, such as that of the mouse mammary tumor virus or the AK virus linked to the CAT gene.

\section{An NF-1-like factor is involved in enhancer function}

We have further analyzed this adipocyte-specific enhancer in several ways in vitro. The 500-bp fragment was dissected into three fragments containing DNA from -5.4 to $-5.0 \mathrm{~kb},-5.4$ to $-5.2 \mathrm{~kb}$, and -5.2 to $-5.0 \mathrm{~kb}$. When linked to the $-63 \mathrm{aP2CAT}$ construct the -5.4 to -5.0 fragment (see Fig. 2B for map) had similar activity to the 500-bp fragment (Fig. 5A). When this fragment $(-5.4$ to $-5.0 \mathrm{~kb})$ was cleaved with Sau3AI, the $5^{\prime}$ half $(-5.4$ to -5.2$)$ retained enhancing activity while the $3^{\prime}$ half had no detectable activity (Fig. 5A). The active 200bp fragment $(5.4-5.2 \mathrm{~kb}$ ) has no detectable activity in 3T3-F442A or 3T3-Ll preadipocytes (not shown), indicating that this DNA contains a significant part of the regulatory action of the whole 500-bp enhancer.

Because the function of cis-acting sequences usually 


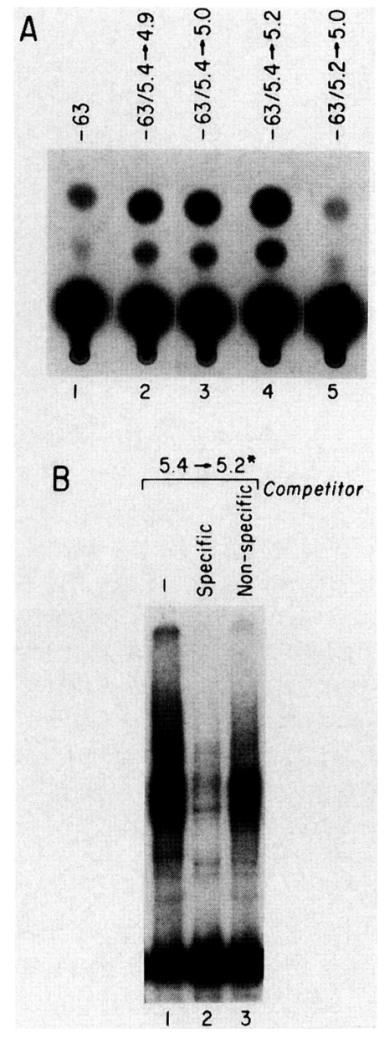

Figure 5. Dissection of the activating function of the enhancer. $|A|$ The restriction enzyme sites indicated in Fig. 2B were utilized to dissect the 500-bp fragment into three smaller fragments. The SstI site generates a 380 -bp fragment $\mid-5.4$ to $-5.0 \mathrm{~kb}$ ), which was then cleaved in half with Sau3AI to generate fragments from -5.4 to $-5.2 \mathrm{~kb}$ and from -5.2 to -5.0 $\mathrm{kb}$. These fragments were ligated to the $-63 \mathrm{aP2CAT}$ construct, and adipocytes were transiently transfected by DEAE-dextran adsorption with $20 \mu \mathrm{g}$ of plasmid DNA. CAT activity was assayed as described in Materials and methods. (Lane 1) $-63 \mathrm{aP2CAT}$; (lane 2) $-63 / 5.4 \rightarrow 4.9 \mathrm{aP}_{2} \mathrm{CAT}_{\text {; }}$ (lane 3) $-63 / 5.4 \rightarrow 5.0 \mathrm{aP} 2 \mathrm{CAT}$; (lane $4-63 / 5.4 \rightarrow 5.2 \mathrm{aP2CAT}$; (lane 5 ) $-63 / 5.2 \rightarrow 5.0 \mathrm{aP2CAT}$. The orientation of enhancer in the constructs used in lanes 4 and 5 had the $-5.2-\mathrm{kb}$ sequence abutted to the the -63 sequence of aP2, while the constructs in lanes 2 and 3 had the $-5.4-\mathrm{kb}$ sequence abutted to the -63 sequence. This experiment was repeated 15 times with four different DNA preparations, and similar results were obtained. $(B)$ The -5.4 - to -5.2-kb fragment was $3^{\prime}$-end-labeled and incubated with $8 \mu \mathrm{g}$ of nuclear extract prepared from adipocytes, and the resulting DNA-protein complexes were analyzed by electrophoresis on a $4 \%$ polyacrylamide gel. The sequence specificity of binding was assessed by the addition of competitor DNAs: (Lane 1) No competitor; (lane 2) 30-fold molar excess of nonradioactive "specific" - 5.4- to - 4.9-kb fragment; (lane 3) 30-fold molar excess of nonradioactive "nonspecific" DNA $\mid-4.3-$ to $-3.6-\mathrm{kb}$ fragment from the aP2 promoter).

depends on the binding of trans-acting factors, we analyzed the binding of adipocyte nuclear extract to the functionally active $-5.4-$ to $-5.2-\mathrm{kb}$ fragment by the mobility-shift DNA-binding assay (Fried and Caruthers 1981; Garner and Rezvin 1981). Figure 5B demonstrates that a single prominent complex is formed and that the formation of this complex can be competed by the addition of nonradioactive DNA in a manner consistent with a sequence-specific DNA-protein interaction.

The contact points between this factor and its binding site were determined by the methylation-interference assay (Siebenlist and Gilbert 1980; Hendrickson and Schleif 1985). The binding sequence, termed ARE for adipocyte regulatory element, is shown in Figure 6A, with the contact points represented as starred residues. Figure $6 \mathrm{~B}$ shows the pattern of sequence-specific binding to a synthetic double-stranded 38-bp ARE using nuclear extracts from adipocytes (lanes 1-4) and preadipocytes (lanes 5-8). Binding activity of similar mobility is present in both cell extracts. While slight differences can be seen in the mobility of these complexes with some extract preparations, we believe this is due to higher proteolytic activity in preadipocyte extracts. The sequence specificity of this interaction is illustrated by the ability of nonradioactive ARE to compete for binding, while a nonspecific oligonucleotide (CAAT-C/EBP) does not compete. As indicated in Figure 6A, the CAAT-C/EBP oligomer differs from the ARE by the presence of an additional $G$ residue in the putative binding site. We also demonstrate that a double point mutation (M1) that converts the sequence... TTGGCAA ... to ... TTGCGAA . . . is unable to compete for binding to the ARE.

Comparison of the ARE and its protein contact points with tables of known nuclear factor-binding sites suggested a relationship to the NF-1 family of transcription factors (TGGCA; Nagata et al. 1983; Borgmeyer et al. 1984; Rawlins et al. 1984). We therefore used adipocyte and HeLa nuclear extracts to compare the binding specificity of the ARE with that of a consensus NF-1 oligomer. Figure $6 \mathrm{~A}$ shows an alignment of the aP2 ARE with two known NF-1-binding sites: the adenovirus 2 origin of replication (NF-1; Leegwater et al. 1985), and a sequence from the mouse albumin gene (ALB; Cereghini et al. 1987; Lichtsteiner et al. 1987). Both of these oligonucleotides compete effectively for the binding of adipocyte extract to the ARE oligomer (Fig. 6C, lanes 1-5); identical results are observed if HeLa nuclear extract is substituted for adipocyte extract (data not shown). In Figure 6C, lanes 6-10, we demonstrate that the ARE can compete for the formation of specific complexes between HeLa nuclear extract (a rich source of NF-1) and a consensus NF-1 oligomer. We have also found that the ARE binds purified, recombinant NF-l /see Materials and methods) in a sequence-specific fashion (data not shown).

We then asked whether antibodies to NF-l would react with the ARE-binding proteins in adipocyte extracts. Figure 7 shows that antibodies directed against the DNAbinding domain of human NF-1 (CTF1; Santoro et al. 1988) are able to dramatically reduce the amount of DNA-protein complex formed. In addition, a small amount of radioactive DNA is "double-shifted" (Fig. 7, arrow) and presumably represents DNA with both NF-1 and antibody bound. In contrast, a control antibody directed against $C / E B P$ has no detectable effect on the band 
A

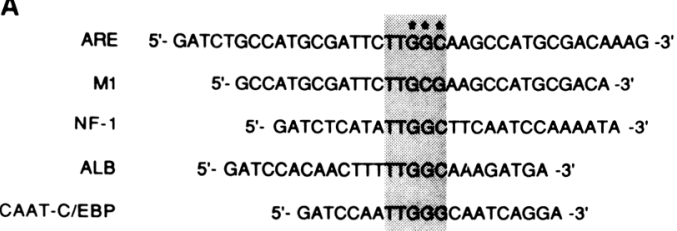

$B$

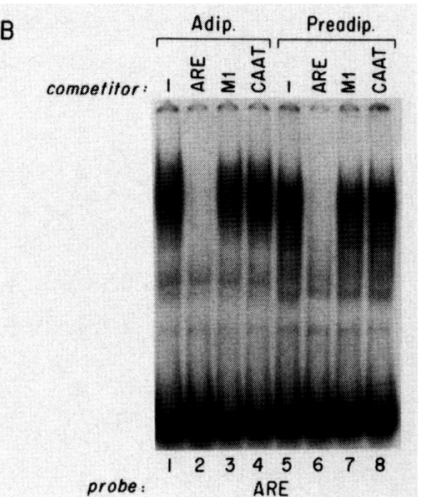

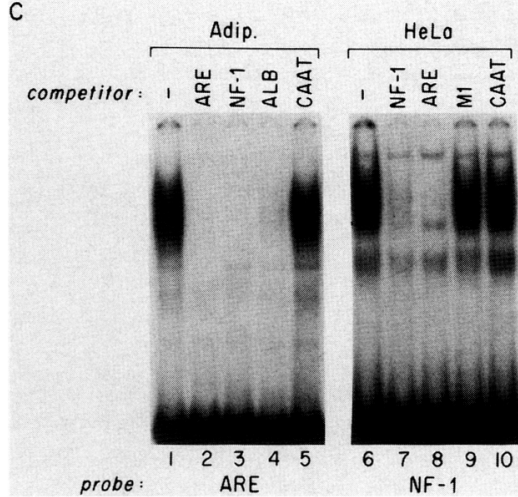

Figure 6. The ARE contains a binding site for NF-1. (A) Oligonucleotides used for gel retardation studies (only one strand shown). ARE contains the major factor-binding site from the $-5.4-$ to $-5.2-\mathrm{kb}$ fragment of the aP2 gene as determined by methylation interference analysis; M1 is a double point mutant of the ARE site. NF-l is the adenovirus type 2 NF-l-binding site (Leegwater et al. 1985). ALB is an NF-1-binding site from the mouse albumin promoter (Cereghini et al. 1987; Lichtsteiner et al. 1987). CAAT-C/EBP is the consensus C/EBP-binding site described by Landschulz et al. (1988). The shaded box highlights similar bases in these various sequences. The stars indicate the contact points (guanosine residues only) determined by methylation interference assay of the - 5.4- to $-5.3-\mathrm{kb}$ fragment of the aP2 gene. Note that the guanosine residues in the other two potential NF-1 sites in this oligonucleotide are clearly not required for DNA binding as assayed by methylation interference. $(B)$ Mobility-shift DNA-binding assays of the ARE oligonucleotide. The ARE oligonucleotide was 5 '-end-labeled, annealed to its complement, and incubated with nuclear extracts from either adipocytes (lanes 1-4) or preadipocytes (lanes 5 and 6); the DNA-protein complexes were resolved by electrophoresis. The competitor oligonucleotides (30-fold molar excess) are indicated above each lane. $(C)$ The ARE (lanes 1-5) or NF-1 (lanes 6-10) oligonucleotides were 5 '-end-labeled, annealed to the appropriate complement, and incubated with nuclear extracts prepared from either adipocytes (lanes 1-5) or HeLa cells (lanes 6-10). The resulting DNA-protein complexes were resolved by electrophoresis. The competitor oligonucleotides (30-fold molar excess) are indicated above each lane.

shift pattern. Together, these data clearly indicate that the ARE-binding factor is a member of the NF-1 transcription/replication factor family (Jones et al. 1987; Santoro et al. 1988).

Finally, we have asked whether the NF-1-like factor that binds to the ARE target sequence plays a functional role in the activity of the adipocyte-specific enhancer. The ARE sequence in the $-63 / 5.4 \rightarrow 4.9 \mathrm{aP2CAT}$ construct was replaced by the double point mutation (M1) that abolished NF-1 binding (Fig. 6A,B). As shown in Table 2, the activity of the enhancer in adipocytes was reduced dramatically $(76 \%)$ as a result of this mutation. The mutant had no observable effect on the minimal level of preadipocyte expression (data not shown). Clearly, the NF-1 site in the 500-bp enhancer plays an important role in the function of this enhancer.

\section{Discussion}

The mechanisms that control adipocyte-specific gene expression are of interest for biological, physiological, and even agricultural reasons. Adipose cells are the major cell types that store energy in higher eukaryotes, and the genes that control adipocyte physiology have a great impact on the regulation of systemic energy balance and lipid metabolism. Pathological conditions that involve adipose tissue, such as obesity, have a profound effect on morbidity and mortality, and it is reasonable to assume that the levels of expression of specific adipocyte genes influence the balance between lipogenesis and lipolysis in a given individual. In the agricultural field, there has been considerable interest in developing genetic methods to alter the balance between lean and fat body mass in feed animals (Boyd and Wray-Cahen 1989), and an

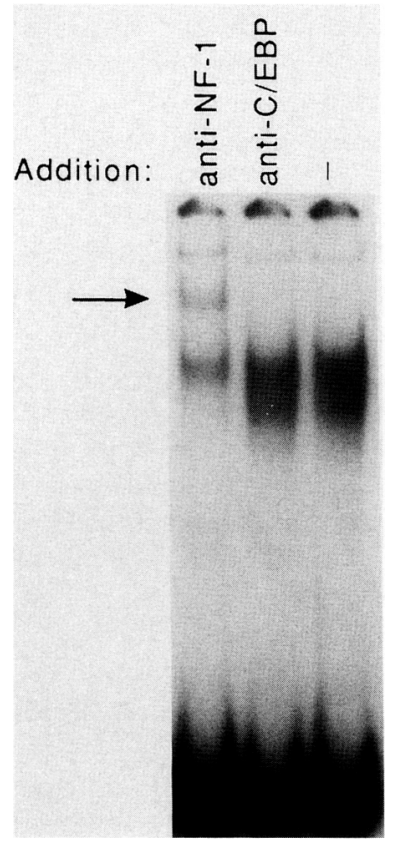

Figure 7. Disruption of ARE binding by antibodies to NF-1. Antisera $(1 \mu l)$ directed against rat C/EBP (Landschulz et al. 1988 ) or human NF-1 were added to $8 \mu \mathrm{g}$ of adipocyte nuclear extract protein and incubated for $15 \mathrm{~min}$ at $4^{\circ} \mathrm{C}$. The treated extracts were then used for DNA-binding mobility-shift assays with the ARE oligomer as a radiolabeled probe. 
Table 2. Effect of mutation in the ARE on enhancer activity in adipocytes

\begin{tabular}{lc}
\hline Vector & CAT conversion $(\%)$ \\
\hline$-63 \mathrm{aP} 2 \mathrm{CAT}$ & 2.6 \\
$-63 / 5.4 \rightarrow 4.9 \mathrm{aP2CAT}$ & $14.9(100)$ \\
$-63 / 5.4 \rightarrow 4.9 \mathrm{MlaP2CAT}$ & $5.5(24)$ \\
\hline
\end{tabular}

The double point mutation (M1) was introduced into the -63 / $5.4 \rightarrow 4.9 \mathrm{aP} 2 \mathrm{CAT}$ vector. Duplicate plates $(100 \mathrm{~mm})$ of preadipocytes or adipocytes were transfected by calcium phosphate coprecipitation with $10 \mu \mathrm{g}$ of plasmid DNA, and CAT activity was assayed as described in Materials and methods. Quantitation was done by phosphorimaging (Molecular Dynamics) of the thin-layer plates with $<20 \%$ variation between duplicate dishes. The experiment was repeated five times with five different preparations of plasmid DNA, and similar results were obtained.

understanding of adipocyte-gene regulation may contribute toward this goal.

Previous studies in cultured cells have demonstrated that the proximal promoter region of the aP2 gene $1-168$ to $+21 ;-247$ to +21 ) can direct expression of a heterologous gene in a differentiation-dependent manner (Distel et al. 1987; Cook et al. 1988). At least two regulatory sites contribute to this expression. An AP-1 site at -120 acts as a transcriptional activator in adipocytes (Distel et al. 1987; Rauscher et al. 1988) and is also required in preadipocytes for responsiveness of this promoter to 8bromo cAMP or to a combination of 8-bromo cAMP and dexamethasone (Cook et al. 1988; Herrera et al. 1989). An additional positive-acting element at -140 (Distel et al. 1987) was demonstrated to be a binding site for C/EBP in adipocytes and a C/EBP-like protein in preadipocytes \{Christy et al. 1989; Herrera et al. 1989). Although the aP2 proximal promoter constructs, $-168 \mathrm{aP2CAT}$ and $-247 \mathrm{aP2CAT}$, are able to direct CAT expression in cultured adipocytes, they are poorly expressed and exhibit no adipose tissue specificity in transgenic mice.

We have employed transient transfection assays of cultured adipocytes to scan a large region of the aP2 gene in search of the element(s) responsible for the high level of tissue-specific expression of this gene. As shown in this report, such an element was found at $-5.4 \mathrm{~kb}$ from the transcription start site. This element has several properties generally considered characteristic of an enhancer. First, it functions at a large distance from the transcription start site of the endogenous aP2 gene. Second, it can function in both orientations, and although we have not moved its position systematically, it is clear that it can work at several different distances from the promoter. Third, it can bestow adipose-differentiation dependence on a heterologous promoter (e.g., SV40 early promoter).

The cell-type specificity of this enhancer is striking. In adipocytes, the 500-bp fragment from -5.4 to $-4.9 \mathrm{~kb}$ stimulates very strong CAT expression from a minimal promoter, i.e., $-63 \mathrm{aP2CAT}$ or an enhancerless SV40 promoter. In contrast, this fragment is not able to stimulate expression from the same promoters in preadipocytes. In addition to this differentiation dependence in cultured cells, the 500-bp enhancer also functions with dramatic tissue specificity in transgenic mice; expression from the $-63 / 5.4 \rightarrow 4.9 \mathrm{aP2CAT}$ construct in adipose tissues was much higher than expression in all other tissues examined. Since many organs (e.g., spleen and thymus) contain a small amount of adipose tissue, even the low level of CAT expression observed in some nonadipose samples may reflect inevitable contamination with adipose cells. Analysis of several CAT constructs containing 5 '-flanking fragments of variable length from the aP2 gene strongly suggests that this enhancer at $-5.4 \mathrm{~kb}$ is the major determinant of adipose tissue-specific expression of the aP2 gene in vivo (Ross et al. 1990).

By dissecting the 500-bp enhancer and assaying its function in cultured cells, we were able to identify a 190-bp fragment capable of conferring differentiation-dependent activation to a minimal promoter. Through mobility-shift and methylation-interference analysis of the 190-bp fragment, we have identified a DNA-binding site (ARE) for a member of the NF-1 protein family. Previously described tissue-specific enhancers have also been shown to contain NF-1 sites (Theisen et al. 1986; Miksicek et al. 1987; Gloss et al. 1989; Jackson et al. 1989). Mutation of the NF-1 site in the adipocyte enhancer reduces its activity dramatically. Because some function is retained, it is possible that other as yet unidentified factors contribute to the activity of the 500-bp enhancer. In support of this idea, we have found that multimers (two to five copies) of the ARE alone are not sufficient to function as an enhancer (data not shown). This is consistent with studies of NF-1 sites in other enhancers, where multimers of these binding sites alone did not activate gene expression (Nowock et al. 1985; Gloss et al. 1989). As individual genes are studied in increasingly greater detail, expression that is qualitatively and quantitatively similar to wild-type levels has often been found to require a combination of several regulatory elements (Fromental et al. 1988; Ondek et al. 1988; Dynan 1989). DNase I footprinting of the adipocyte enhancer reveals the presence of at least two other prominent factors (present in HeLa, preadipocyte, and adipocyte extracts) in addition to NF-1 that bind to this 500-bp enhancer. Detailed analyses of the function of the nonNF-1 sites in the adipocyte enhancer is currently under way.

A crucial question at this point is whether the adipocyte NF-1 serves to regulate this enhancer or is an important though nonregulating component. For the adipocyte NF-1 to play a regulatory role, this would imply either a tissue-specific NF-1 or a tissue-specific structural change, covalent or noncovalent, in a constitutive NF-1. It is important to note that the NF-1 family includes several members with wide tissue distribution (Borgmeyer et al. 1984; Gil et al. 1988; Santoro et al. 1988; Rupp et al. 1990) and also includes some molecular species that are restricted to certain tissues (Lichtsteiner et al. 1987; Paonessa et al. 1988). Preliminary data demonstrate that at least one member of the NF-1 family is induced at the mRNA level during adipocyte differentiation (Y.D. Halvorsen and B.M. Spiegelman, unpubl.). 
Whether this gene product regulates the function of the enhancer remains to be determined.

The enhancer described here represents the first sequence demonstrated to endow fat-cell specificity to a heterologous gene. Because adipocyte differentiation is accompanied by the activation of many genes (Spiegelman and Green 1980), it is of acute interest to know whether the NF-1 factor and other, as yet unidentified, cis- and trans-acting components functioning here play important roles in the regulation of other fat-cell-specific genes. Because a single, closely related family of factors can activate many genes in another mesoderm lineage, muscle (Davis et al. 1987), it is important to learn whether a parallel regulatory system exists for fat.

The results presented here also have implications for the role of the proximal promoter elements, including the binding sites for AP-1 and C/EBP, in tissue-specific gene expression. Because C/EBP can bind to several adipocyte-specific promoters (Christy et al. 1989; Kaestner et al. 1990) and is only expressed following adipocyte differentiation (Christy et al. 1989; Herrera et al. 1989), it has been suggested that C/EBP plays an important role in adipose-specific gene regulation and energy metabolism (Christy et al. 1989; McKnight et al. 1989; Kaestner et al. 1990 . As stated above, the aP2 proximal promoter constructs $(-168 \mathrm{aP2CAT}$ or $-247 \mathrm{aP2CAT})$ that contain the AP-1- and C/EBP-binding sites are not able to direct tissue-specific expression in transgenic mice. Because our $-63 / 5.4 \rightarrow 4.9 \mathrm{aP2CAT}$ construct is expressed in a cell- and tissue-specific fashion but lacks these binding sites, it appears that the AP-1 and C/EBP factors are not necessary for the tissue-specific expression of this adipocyte gene. The AP-1 and C/EBP sites may well function as quantitative modulators of aP2 gene expression and may be involved in the transcriptional response of this gene to a variety of hormones or metabolic states.

The demonstration of a DNA element that directs strong and specific expression to adipose cells in vivo will open several interesting lines of genetic experimentation relating to the function of this cell type in normal physiology and disease. It should be possible to use this enhancer to direct adipose-specific expression of various proteins that affect adipocyte function and regulate lipolysis and lipogenesis. For example, new experimental models of lipodystrophy or obesity might be brought about by overexpression of the $\beta$-adrenergic or $\alpha 2$-adrenergic receptors, respectively (Gilman et al. 1985; Mauriege et al. 1987). Alternatively, the relationship between obesity and diabetes in several obese/diabetic mouse models (Coleman 1982) could be probed by directly suppressing adipose cell formation and/or lipid accumulation through the delivery of toxins or various receptors affecting lipid accumulation. Direct genetic manipulation of adipose tissue in vivo should now be possible.

\section{Materials and methods}

Cell culture, transfections, and CAT assays

3T3-F442A cells were cultured as described previously (Green and Kehinde 1974, 1976), except that preadipocytes were grown with $10 \%$ calf serum instead of the cat and calf serum mixture. Cells were transfected by the DEAE-dextran method exactly as described (Vogt 1974; Wilkison et al. 1990). In some experiments, cells were transfected by a modification of the calcium phosphate method (Graham and van der Eb 1973). Fully differentiated adipocytes (4-7 days postconfluence) in 100-mm dishes were washed with $5 \mathrm{ml}$ of $1 \mathrm{~mm}$ EDTA in PBS and refed with DMEM, 10\% fetal calf serum, and $5 \mu \mathrm{g} / \mathrm{ml}$ of insulin 2 to $4 \mathrm{hr}$ before application of the DNA-calcium phosphate coprecipitate that was formed as described (Graham and van der Eb 1973). After incubation for 3-6 hr, the media/precipitate was removed and cells were shocked with $10 \%$ glycerol in DMEM for $3 \mathrm{~min}$, rinsed with $10 \mathrm{ml}$ of PBS, and refed with DMEM supplemented with $10 \%$ fetal calf serum and $5 \mu \mathrm{g} / \mathrm{ml}$ of insulin. The cells were refed $12 \mathrm{hr}$ later and collected $36 \mathrm{hr}$ after the glycerol shock. Extracts were prepared from cells by four cycles of freeze-thaw and assayed for CAT activity (Gorman et al. 1982; Wilkison et al. 1990). Deacetylase activity was destroyed by heating the extracts at $60^{\circ} \mathrm{C}$ for $7 \mathrm{~min}$ (Mercola et al. 1985). Half of the extract $\sim \sim 100 \mu \mathrm{g}$ protein) was assayed for $1 \mathrm{hr}$ (when calcium phosphate precipitation was used for transfection) or $3 \mathrm{hr}$ (when DEAE-dextran was used for transfection) at $37^{\circ} \mathrm{C}$. Transient transfections were repeated a minimum of five times, and at least two different plasmid preparations were tested. To normalize the transfection efficiency, the human growth hormone gene, driven by the mouse metallothionein promoter, was used as an internal control (pXGH5; Nichols Institute, San Juan Capistrano, CA). Some CAT assays were quantitated using a phosphorimaging device (Molecular Dynamics).

Nuclear extracts, mobility-shift DNA-binding assays, and methylation interference assays

Nuclear extracts were prepared as described by Shapiro et al. (1988). Mobility-shift DNA-binding assays (Fried and Caruthers 1981; Garner and Rezvin 1981) of oligonucleotide probes were performed as described by Distel et al. (1987). When the 190-bp restriction fragment was used as a probe, the amount of carrier poly[d(I-C)] was increased to $2 \mu \mathrm{g}$ with $8 \mu \mathrm{g}$ of protein in $20 \mu \mathrm{l}$. Oligonucleotides were purchased from Midland Certified $\mathrm{Re}$ agent Company (Midland, Texas) and used without further purification. Recombinant human NF-1 (encoded by the CTF1 cDNA; Santoro et al. 1988) was purified by DNA-affinity chromatography from baculovirus-infected insect cells and was generously provided by Dr. Ronald Hay (University of St. Andrews, Scotland). NF- 1 antibodies were directed against the DNA-binding domain of recombinant human NF-l produced in baculovirus-infected cells and were the kind gift of Dr. Ronald Hay.

\section{Plasmids}

The phage used for the isolation of the aP2 $5^{\prime}$-flanking sequences was described in Hunt et al. (1986). The HindIII at the position -63 in the $-63 \mathrm{aP2CAT}$ vector (Distel et al. 1987) was used for insertion of the fragments of the aP2-flanking region by blunt-end ligation of the filled-in restriction sites. For the construct involving the enhancerless SV40 promoter, the BglII site at the 5 ' end of the promoter was used (Celander and Haseltine 1984). The M1 mutation was introduced into the -5.4 - to - 4.9-kb fragment using the Amersham mutagenesis kit (Taylor et al. 1985). The RSVCAT and AU3CAT vectors were described in Celander and Haseltine (1984).

\section{Transgenic animals}

DNA injections into Swiss Webster (SW) mouse one-cell zygotes and implantation into pseudopregnant foster mothers 
were performed as described previously (Choi et al. 1987). SW mice were purchased from the NCI Frederick Animal Production Facility (Frederick, Maryland). DNA fragments for microinjection were isolated from the vector by electroelution from agarose gels. Positive transgenic animals were identified by polymerase chain reaction (PCR). Copy number was estimated by dot blots of genomic DNA. Southern blot analysis was also perfomed to ensure that no gross rearrangement of the transgenes had occurred.

\section{Acknowledgments}

We thank Ulla Hansen, Gregory Robinson, Lillian Clark, and Rebecca Sundseth for helpful comments and suggestions during the execution of this work and Ronald Hay for providing us with purified baculovirus-expressed NF-1 and anti-NF-1 antibodies. Antibodies to rat C/EBP were kindly provided by Steve McKnight. We thank Chuck Stiles, Julia Alberta, and Chiayeng Wang for use and help with the phosphorimager. We also thank Ms. Adah Levens for assistance in the preparation of this manuscript. This work was supported by grants from the National Institutes of Health (Dk31405; B.M.S.) and March of Dimes (S.R.R.). S.R.R. is a Leukemia Society of America Scholar, and B.M.S. is an Established Investigator of the American Heart Association.

The publication costs of this article were defrayed in part by payment of page charges. This article must therefore be hereby marked "advertisement" in accordance with 18 USC section 1734 solely to indicate this fact.

\section{References}

Bernlohr, D.A., C.W. Angus, M.D. Lane, M.A. Bolanowski, and T.J. Kelly, Jr. 1984. Expression of specific mRNA during adipose differentiation: Identification of an mRNA encoding a homologue of myelin P2 protein. Proc. Natl. Acad. Sci. 81: 5468-5472.

Bernlohr, D.A., M.A. Bolanowski, T.J. Kelly, Jr., and M.D. Lane. 1985. Evidence for an increase in transcription of specific mRNAs during differentiation of 3T3-L1 adipocytes. $J$. Biol. Chem. 260: 5563-5567.

Borgmeyer, U., J. Nowock, and A.E. Sippel. 1984. The TGGCAbinding protein: A eukaryotic nuclear protein recognizing a symmetrical sequence on double-stranded linear DNA. $\mathrm{Nu}$ cleic Acids Res. 12: 4295-4311.

Boyd, R.D. and D. Wray-Cahen. 1989. In Biotechnology for control of growth and product quality in swine implications and acceptability (ed. P. van der Wal, G.J. Nieuwhof, and R.D. Politiek), pp. 21-33. Pudoc Wageningen, Netherlands.

Celander, D. and W.A. Haseltine. 1984. Tissue-specific transcription preference as a determinant of cell tropism and leukaemogenic potential of murine retroviruses. Nature 312: 159-162.

Cereghini, S., M. Raymondjean, A.G. Carranca, P. Herbomel, and $M$. Yaniv. 1987. Factors involved in control of tissuespecific expression of albumin gene. Cell 50: 627-638.

Chapman, A.B., D.M. Knight, B.A. Dieckman, and G.M. Ringold. 1984. Analysis of gene expression during differentiation of adipogenic cells in culture and hormonal control of the developmental program. I. Biol. Chem. 259: 1554815555.

Choi,Y., D.H. Henrad, I. Lee, and S.R. Ross. 1987. The mouse mammary tumor virus long terminal repeat directs expres- sion in epithelial and lymphoid cells of different tissues in transgenic mice. I. Virol. 61: 3013-3019.

Christy, R.J., V.W. Yang, J.M. Ntambi, D.E. Geiman, W.H. Landschulz, A.D. Friedman, Y. Nakabeppu, T.J. Kelly, and M.D. Lane. 1989. Differentiation-induced gene expression in 3T3-L1 preadipocytes: CCAAT/enhancer binding protein interacts with and activates the promoters of two adipocytespecific genes. Genes \& Dev. 3: 1323-1335.

Coleman, D.L. 1982. Diabetes-obesity syndrome. In The mouse in biomedical research, vol. IV, pp. 125-132. Academic Press, New York.

Cook, J.S., J.J. Lucas, E. Sibley, M.A. Bolanowski, R.J. Christy, T.J. Kelly, and M.D. Lane. 1988. Expression of the differentiation induced gene for fatty acid binding protein is activated by glucocorticoid and cAMP. Proc. Natl. Acad. Sci. 85: 2949-2953.

Cook, K.S., C.R. Hunt, and B.M. Spiegelman. 1985. Developmentally regulated mRNA in 3T3-adipocytes: Analysis of transcriptional control. J. Cell. Biol. 100: 514-520.

Davis, R.L., H. Weintraub, and A.B. Lassar. 1987. Expression of a single transfected cDNA converts fibroblasts to myoblasts. Cell 51: 987-1000.

Distel, R., H.-S. Ro, B.S. Rosen, D. Groves, and B.M. Spiegelman. 1987. Nucleoprotein complexes that regulate gene expression in adipocyte differentiation: Direct participation of c-fos. Cell 49: 835-844.

Djian, P., M. Phillips, and H. Green. 1985. The activation of specific gene transcription in adipose conversion of $3 \mathrm{~T} 3$ cells. J. Cell. Physiol. 124: 554-556.

Doglio, A., C. Dani, P. Grimaldi, and G. Aihaud. 1986. Growth hormone regulation of the expression of differentiation-dependent genes in preadipocyte Ob1771 cells. Biochem. I. 238: $123-129$.

Dynan, W. 1989. Modularity in promoters and enhancers. Cell 58: $1-4$.

Fried, M. and Cruthers, D.M. 1981. Equilibria and kinetics of lac repressor-operator interactions by polyacrylamide gel electrophoresis. Nucleic Acids Res. 9: 6505-6525.

Fromental, C., M. Kanno, H. Nomiyama, and P. Chambon. 1988. Cooperativity and hierarchical levels of functional organization in the SV40 enhancer. Cell 54:943-953.

Garner, M.M. and A. Revzin. 1981. A gel electrophoresis method for quantifying the binding of proteins to specific DNA regions: Application to components of the Escherichia coli lactose operon regulatory system. Nucleic Acids Res. 9: 3047-3060.

Gil, G., J.R. Smith, J.L. Goldstein, C.A. Slaughter, K. Orth, M.S. Brown, and T.F. Osborne. 1988. Multiple genes encode nuclear factor 1-like proteins that bind to the promoter for 3-hydroxy-3-methylglutaryl-coenzyme A reductase. Proc. Natl. Acad. Sci. 85: 8963-8967.

Gilman, A.G., L.S. Goodman, T.W. Rall, and F. Murad. 1985. Pharmacological basis of therapeutics, 7 th ed. Macmillan, New York.

Gloss, B., G.M. Yeo, M. Meisterenst, L. Rogge, E.L. Winnacker, and H.U. Bernard. 1989. Clusters of nuclear factor I binding sites identify enhancers of several papillomavinuses but alone are not sufficient for enhancer function. Nucleic Acids Res. 17: 3519-3533.

Gorman, C.M., C.-F. Moffat, and B.H. Howard. 1982. Recombinant genomes which express chloramphenicol acetyltransferase. Mol. Cell. Biol. 2: 1044-1051.

Graham, F.L. and A.J. van der Eb. 1973. A new technique for the assay of infectivity of human adenovirus 5 DNA. Virology 52: $456-467$.

Green, H. 1979. Adipose conversion: A program of differentia- 
tion. In Obesity, cellular and molecular aspects (ed. G. Ailhaud), pp. 15-25. Editions INSERM, Paris.

Green, H. and O. Kehinde. 1974. Sublines of mouse 3T3 cells that accumulate lipid. Cell 1: 113-116.

. 1976. Spontaneous heritable changes leading to increased adipose conversion in 3T3 cells. Cell 7: 105-113.

Hendrickson, W. and R. Schlief. 1985. A dimer of AraC protein contracts three adjacent major groove regions of the araI DNA site. Proc. Natl. Acad. Sci. 82: 3129-3133.

Herrera, R., H.S. Ro, G.S. Robinson, K.G. Xanthopoulos, and B.M. Spiegelman. 1989. A direct role for C/EBP and the APl-binding site in gene expression linked to adipocyte differentiation. Mol. Cell. Biol. 9: 5331-5339.

Hunt, C., J.H.-S. Ro, H.-Y. Min, D.E. Dobson, and B.M. Spiegelman. 1986. Adipocyte P2 gene: Developmental expression and homology of $5^{\prime}$ - flanking sequences among fat cell-specific genes. Proc. Natl. Acad. Sci. 83: 3786-3790.

Jackson, P.D., T. Evans, J.M. Nickol, and G. Felsenfeld. 1989. Developmental modulation of protein binding to beta-globin gene regulatory sites within chicken erythrocyte nuclei. Genes \& Dev. 3: 1860-1873.

Jones, K.A., J.T. Kadonaga, P.J. Rosenfeld, T.J. Kelly, and R. Tiian. 1987. A cellular DNA-binding protein that activates eukaryotic transcription and DNA replication. Cell 48: 7989.

Kaestner, K.H., R.J. Christy, and M.D. Lane. 1990. Mouse insulin-responsive glucose transporter gene: Characterization of the gene and trans-activation by the CCAAT/enhancer binding protein. Proc. Natl. Acad. Sci. 87: 251-255.

Landschulz, W.H., P.F. Johnson, E.Y. Adashi, B.J. Graves, and S.L. McKnight. 1988. Isolation of a recombinant copy of the gene encoding C/EBP. Genes \& Dev. 2: 786-799.

Leegwater, P.A.J., W. Van Driel, and P.C. Van der Vliet. 1985. Recognition site of nuclear factor I, a sequence-specific DNA-binding protein from HeLa cells that stimulates adenovirus DNA replication. EMBO /. 4: 1515-1521.

Lichtsteiner, S., J. Wuarin, and U. Schibler. 1987. The interplay of DNA-binding proteins on the promoter of the mouse albumin gene. Cell 51: 963-973.

Matarese, V. and D.A. Bernlohr. 1988. Purification of murine adipocyte lipid-binding protein. Characterization as a fatty acid- and retinoic acid-binding protein. 7 . Biol. Chem. 263: 14544-15551.

Mauriege, P., J. Galitzky, M. Berlan, and M. Lafontan. 1987. Heterogeneous distribution of beta and alpha-2 adrenoceptor binding sites in human fat cells from various fat deposits: Functional consequences. Eur. J. Clin. Invest. 17: 156-165.

McKnight, S.L., M.D. Lane, and S. Gluecksohn-Waelsch. 1989. Is CAAT/enhancer-binding protein a central regulator of energy metabolism? Genes \& Dev. 3: 2021-2024.

Mercola, M., J. Goverman, C. Mirell, and K. Calame. 1985. Immunoglobulin heavy-chain enhancer requires one or more tissue-specific factors. Science 227: 266-270.

Miksicek, R., U. Borgmeyer, and J. Nowock. 1987. Interaction of the TGGCA-binding protein with upstream sequences is required for efficient transcription of mouse mammary tumor virus. EMBO I. 6: 1355-1360.

Nagata, K., R.A. Guggenheimer, and J. Hurwitz. 1983. Specific binding of a cellular DNA replication protein to the origin of replication of adenovirus DNA. Proc. Natl. Acad. Sci. 80: 6177-6181.

Negrel, R., P. Grimaldi, and G. Ailhaud. 1978. Establishment of preadipocyte clonal line from epididymal fat $\mathrm{pad}$ or $\mathrm{ob} / \mathrm{ob}$ mouse that responds to insulin and to lipolytic hormones. Proc. Natl. Acad. Sci. 75: 6054-6058.

Nowock, J., U. Borgmeyer, A.W. Puschel, R.A.W. Rupp, and
A.E. Sippel. 1985. The TGGCA protein binds to the MMTVLTR, the adenovirus origin of replication, and the BK virus enhancer. Nucleic Acids Res. 13: 2045-2061.

Ondek, B., L. Gloss, and W. Herr. 1988. The SV40 enhancer contains two distinct levels of organization. Nature 333: 4045.

Paonessa, G., F. Gounari, R. Frank, and R. Cortese. 1988. Purification of a NF-1-like DNA-binding protein from rat liver and cloning of the corresponding cDNA. EMBO $/$. 7:31153123.

Phillips, M., P. Djian, and H. Green. 1986. The nucleotide-sequence of three genes participating in the adipose differentiation of 3T3 cells. J. Biol. Chem. 261: 10821-10827.

Rauscher, F.J. III, L.C. Sambucetti, T. Curran, R.J. Distel, and B.M. Spiegelman. 1988. Common DNA binding site for fos protein complexes and transcription factor AP-1. Cell 52: $471-480$.

Rawlins, D.R., P.J. Rosenfeld, R.J. Wides, M.D. Challberg, and T.J.J. Kelly. 1984. Structure and function of the adenovirus origin of replication. Cell 37: 309-319.

Ross, S.R., R.A. Graves, A. Greenstein, K.A. Platt, H.-L. Shyu, B. Mellovitz, and B.M. Spiegelman. 1990. A fat-specific enhancer is the primary determinant of adipocyte $\mathrm{P} 2$ (aP2) gene expression in vivo. Proc. Natl. Acad. Sci. 87: 9590-9594.

Rupp, R.A., U. Kruse, G, Multhaup, U. Gobel, K. Beyreuther, and A.E. Sippel. 1990. Chicken NFI/TGGCA proteins are encoded by at least three independent genes: NFI-A, NFI-B and NFI-C with homologues in mammalian genomes. $\mathrm{Nu}$ cleic Acids Res. 18: 2607-2616.

Santoro, C., N. Mermod, P.C. Andrews, and R. Tiian. 1988. A family of human CCAAT-box-binding proteins active in transcription and DNA replication: Cloning and expression of multiple cDNAs. Nature 334: 218-224.

Shapiro, D.J., P.A. Sharp, W.W. Wahli, and M.J. Keller. 1988. A high- efficiency HeLa cell nuclear transcription extract. Gene 7: 47-55.

Siebenlist, U. and W. Gilbert. 1980. Contacts between Escherichia coli RNA polymerase and an early promoter of phage T7. Proc. Natl. Acad. Sci. 77: 122-126.

Spiegelman, B.M. and H. Green. 1980. Control of specific protein biosynthesis during the adipose conversion of $3 \mathrm{~T} 3$ cells. I. Biol. Chem. 255: 8811-8818.

Spiegelman, B.M., M. Frank, and H. Green. 1983. Molecular cloning of mRNA from 3T3-adipocytes. Regulation of mRNA content for glycerophosphate dehydrogenase and other differentiation-dependent proteins during adipocyte development. J. Biol. Chem. 258: 10083-10089.

Taylor, J.W., J. Ott, and F. Eckstein. 1985. The rapid generation of oligonucleotide-directed mutations at high frequency using phosphorothioate-modified DNA. Nucleic Acids Res. 13: 8764-8785.

Theisen, M., A. Stief, and A.E. Sippel. 1986. The lysozyme enhancer: Cell-specific activation of the chicken lysozyme gene by a far-upstream DNA element. EMBO J. 5: 719-724.

Vogt, P.K. 1974. DEAE-dextran: Enhancement of cellular transformation induced by avian sarcoma viruses. Virology 33: $175-177$.

Wilkison, W.O., H.-Y. Min, K.P. Claffey, B.L. Satterberg, and B.M. Spiegelman. 1990. Control of the adipsin gene in adipocyte differentiation. Identification of distinct nuclear factors binding to single- and double-stranded DNA. I. Biol. Chem. 265: 477-482.

Yang, V.W., R.J. Christy, J.S. Cook, T.J. Kelly, and M.D. Lane. 1989. Mechanism of regulation of the 422 (aP2) gene by cAMP during preadipocyte differentiation. Proc. Natl. Acad. Sci. 86: 3629-3633. 


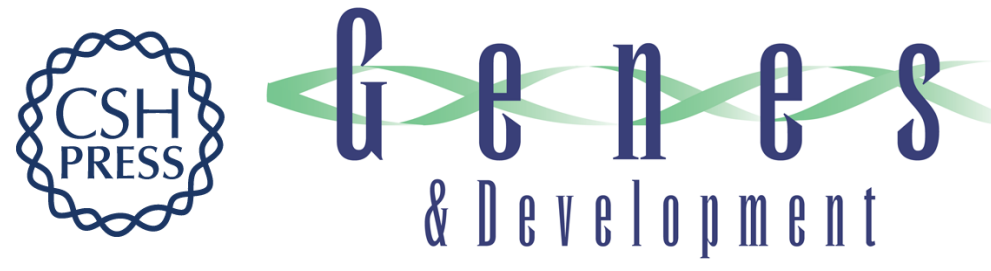

\section{Identification of a potent adipocyte-specific enhancer: involvement of an NF-1-like factor.}

R A Graves, P Tontonoz, S R Ross, et al.

Genes Dev. 1991, 5:

Access the most recent version at doi:10.1101/gad.5.3.428

References This article cites 58 articles, 28 of which can be accessed free at:

http://genesdev.cshlp.org/content/5/3/428.full.html\#ref-list-1

License

Email Alerting

Service

Receive free email alerts when new articles cite this article - sign up in the box at the top right corner of the article or click here.

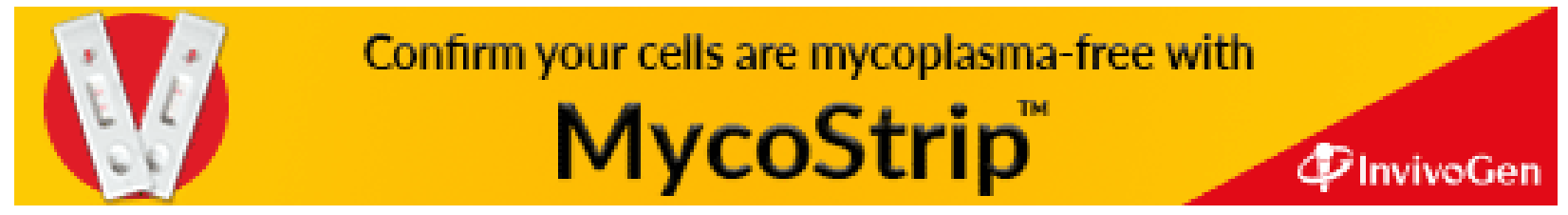

